\title{
Differential Effectiveness of Lifestyle Modification and Nutrition Education in Enhancing Nutritional Knowledge and Healthy Eating Practices Among Pupils, Nigeria
}

\author{
Kolawole Olanrewaju Ayodele, $\mathrm{PhD}^{1}$, Rita Nkiruka Ezeokoli, $\mathrm{PhD}^{2}$ \& Ogechukwu Emmanuel Okondu ${ }^{3}$ \\ ${ }^{1}$ Department of Education, Babcock University, Ilishan, Ogun State, Nigeria \\ ${ }^{2}$ Department of Social Work \& Human Services, Babcock University, Ilishan, Ogun State, Nigeria \\ ${ }^{3}$ Department of Public Health, Babcock University Ilishan-Remo, Ilishan, Ogun State, Nigeria \\ Correspondence: Kolawole Olanrewaju Ayodele, Department of Education, Babcock University, Ilishan, Ogun \\ State, Nigeria. Tel: 234-805-567-6925. E-mail: ayodelek@babcock.edu.ng
}

Received: July 10, 2019 Accepted: September 2, 2019 Online Published: September 16, 2019

doi:10.5539/gjhs.v11n11p84 URL: https://doi.org/10.5539/gjhs.v11n11p84

\begin{abstract}
The eating patterns of children in the last few decades along with the general population have changed. The population now consume a greater amounts of high-fat, high-salt, and high-sugar foods which have constituted numerous health challenges. This study examined the differential effectiveness of nutrition education and life modification intervention on healthy eating practices among primary school pupils in Ikenne Local Government Area of Ogun State, Nigeria.

A sample of 240 primary 5 and 6 pupils from 3 primary schools were randomly selected from three public primary schools in Ikenne LGA of Ogun State, Nigeria. One standardized instrument was used in collecting data while analysis of covariance statistical method was used to analyze the generated data.

Results showed a significant differential effectiveness of lifestyle modification (LM), nutrition education (NE) and when combined as a treatment (LM/NE) enhanced participants' nutritional knowledge and healthy eating behaviour. The study also revealed that female pupils in all the three groups benefited more compared to their male counterparts after treatment.

This study concluded that the treatment programmes are veritable tools in enhancing the knowledge of personal food intake and this knowledge will increase the individuals' potential and decisions to continue to utilize nutrition information in the choice of daily food and monitoring salt and sugar intake to prevent diet-related illness. Therefore, enhancing healthy living among the citizens.
\end{abstract}

Keywords: Healthy eating practices, life modification, nutrition education, primary school pupils

\section{Introduction}

All over the world today, the choice of food and healthy eating among youths are a complex issue. Generally, daily food selections by individuals is to help provides the body with nutritional sustenance and to reduce the feeling of hunger. Researchers like Ayodele and Oke (2017), Chadwick, Crawford, and Ly (2013) affirmed that the choice of food by individuals are influenced by both physiological and psychological factors. Society may be predisposed to making food choices based on foods that taste pleasant, such as sweet and salt foods, while avoiding sour and bitter foods (Chadwick, Crawford, \& Ly, 2013).Food is essential for the existence of all living things. Our bodies need food for energy production, to survive and to remain strong. For good health you need a balanced diet; this means that you do not just eat one food item, but you eat a range of foods so that you can get everything your body needs. The health of individual will be improved and healthier if they are given a healthy, diet rich in protein, energy and vitamins (Ayodele \& Oke, 2018).

Good nutrition can play a role in the prevention of several chronic diseases, including obesity, coronary heart disease, and certain type of cancer, stroke, and type two diabetes. For this reason, nutrition is a priority area for humans and healthy eating habits should be established and maintained during adolescence (Demory-luce \& Motil, 2016). Nutritional related disorders common among adolescents according to Anabwani (2015) are tooth decay, obesity, iron deficiency anaemia, calcium deficiency, iodine deficiency, bulima nervosa and anorexia nervosa. 
Adolescent eating habits and pattern are at first under the influence of the family situations but changes when they are admitted into secondary schools. The poor nutritional status of the adolescent has been attributed to many factors including; low meal frequency, high consumption of sweetened beverages, increased consumption of energy dense food, increased consumption of food away from home (with peers), skipping meals particularly breakfast, consumption of high dense fatty and sugary fast foods, eating meals characterized by low content of fruits and vegetables, adopting unconventional dietary practices such as cutting down the sizes of meal in an attempt to lose weight and attain a slim body figure particularly among females (Buxton, 2013).

Skardal, Western, Ask and Overby (2014) identified that although the knowledge of healthy eating habits can affect food choices by the adolescent child. A study by Fitzgerald, Heary, Nixon, Kelly (2010) identified three key factors as influencing the adolescent food choices and this include intra individual factors, intra familial factors and extra familial factors. Food choices established during adolescence tend to persist into adulthood with consequences for long term health. This transitional period of the adolescent child can provide an opportunity to prepare for a healthy and productive life and to prevent the onset of nutritional related chronic diseases in adult life if adequate measures are put in place (Fitzgerald, et al, 2010).

Dietary patterns of adolescents and young adults has been studied widely and reported in the literature as being associated with obesity, frequent snacking and meal skipping particularly breakfast (Isa \& Masuri, 2011). Lokadhia (2013) reported that students make poor food choices due to lack of nutritional knowledge and understanding of their dietary requirements. There was prevalence of physical signs of malnutrition which indicated that the students were unhealthy and could impact negatively on their academic performance (Lokadhia, 2013).

Over the past decades, children's eating patterns, along with those of the general population, have changed to include a greater amounts of high-fat, high-salt, and high-sugar foods (Stevenson, Doherty, Barnett, Muldoon, \& Trew, 2007). These changes can be attributed to changing lifestyles, greater availability of energy-dense food options, and the targeting of food advertising to children, amongst other factors (Stevenson et al., 2007). The recent Canadian Health Measures Survey (CHMS) indicates that a quarter of Canadian children and youth are overweight or obese (Colley et al., 2011; Winson, 2010).

The numerous health challenges associated with childhood overweight and obesity have raised global awareness to target intervention efforts and develop effective population-based programs and policies to combat this epidemic early in life (Wang \& Lim, 2012). Studies have established that the long-term health of a child is linked to nutritional habits beginning early in life, and encouraging healthful eating among children should be a priority in fighting childhood obesity and later-life disease risk (Li, Goran, Kaur, Nollen, \& Ahluwalia, 2007; Nonnemaker, Morgan-Lopez, Pais, \& Finkelstein, 2009; Winson, 2008).

Study conducted in Greece among university students to determine their eating habits at or away from home found that students living at home did not show major changes in their eating habits since starting university. Students living away from family home had made some negative changes. They decreased their weekly consumption of fresh fruits, cooked and the raw vegetables, oily fish, sea foods, pulses and olive oil while they increased their sugar, wine, alcohol and fast food intake. This implied that moving away from home and assuming responsibility for food preparation and purchase for the first time affect dietary habits (Lokadhia, 2013).

Body weight concerns, dieting, food knowledge, parental control, maternal education, family meals, eating with peers, age and gender are factors that affect food choices among Greek adolescents. Despite the fact that certain traditions remain strong in rural Greece, globalization seems to be eroding them and to be leading to food modifications that are not compatible with the traditional Mediterranean diet and healthy eating. Understanding adolescents' perceptions towards food and nutrition along with factors that influence adolescent food behavior might help to promote health among adolescents and improve quality of life (Bargiota, Delizona, Tsitouras \& Koukoulis, 2013).

Research on the promotion of healthy eating among children by influencing attitudes and behaviors, stresses the need to encourage repeated exposure to a wide variety of foods and to address children's self-efficacy for choosing healthier foods (Chu et al., 2013; Cunningham-Sabo \& Lohse, 2014). Studying healthy eating among children from their own perspectives has become increasingly important, not only to inform effective interventions to reduce childhood overweight and obesity, but also to influence children's understanding of what, when, and how much to eat (Pai \& Contento, 2014). Two of such healthy eating promotion will be addressed in this study, which are nutrition education and healthy eating life modification.

Nutrition education is one of the effective intervention strategies for bringing about nutritional knowledge, 
attitudinal and behavioral change in the individual. Nutrition education has been reported to be one of the effective means of alerting of individuals of the need for nutrition improvement and step towards improving food habits (Audu, 2013; Onyeneke, Nwajiuba, Igberi, Amadi, Anosike, Oko-Isu., Munonye, Uwadoka,. \& Adewale, 2019 ).The ultimate goal of nutrition education according to leverton (1974), is to aid individual to effectively apply nutritional knowledge, attitudes beliefs and practices and modify their diets. Lewis (1976) cited by Audu (2013) posited that the goal of nutrition education is to produce nutritionally sound decision makers who are motivated, knowledgeable, skilled and willing to choose proper nutrition alternative. It is therefore believed that a well planned and well delivered nutrition education programme targeted at youths may produce future leaders who are motivated, knowledgeable, and skilled and who can be empowered to make informed decisions on nutritional issues.

Healthy lifestyle modifications on the other hand include weight management and prudent diet, which have been identified as key components of healthy living. Besides, the addition of psychological component further improved the effectiveness of diet and weight management interventions (Stephens, Cobiac, \& Lennert, 2014). The combination of diet, weight management and psychological approaches is commonly referred as lifestyle modification program. Researchers like Baker, Simpson, Lloyd, Bauman, and Singh (2011), Wadden, Webb, Moran, and Bailer (2012) confirmed the effectiveness of lifestyle modifications. According to them, lifestyle interventions on average achieved $7-10 \%$ weight loss with the additional benefits of prevention or resolution of obesity-related comorbidities. Also, the results of lifestyle modification programs for weight loss have been promising (Barte et al., 2011; Wadden, 2012).

However, people may choose an assortment of foods based on past impulsive behavioral habits, social influence, and interpersonal influences in the community. Food selections are also influenced by individuals in the immediate environment such as friends and associates (McFerran, Dahl, Fitzsimons, \& Morales, 2013). Food preferences are eventually integrated into daily behavior and become habits (Franchi, 2012). The desire to select a particular food may be based on food taste, ability to purchase food based on price, or the desire to consume organic foods based on personal tendency (Kjarnes, 2012). People make food choices on what they believe is nutritious, and food labels are one way consumers use to determine the nutritional value of foods.

Most of the unhealthy eating habits cultivated while in school have both immediate and delayed consequences that are detrimental to their general wellbeing (Onyiriuka, Umuru, \& Ibeawuchi, 2013). Chadwick et al. (2013) supported the idea of health education programs that focus on educating consumers on behavior modification, facilitating long-term changes, and encouraging people to eat a balanced diet of foods from all food groups. Therefore, there is the need to assess the effect of nutrition education and life modification intervention on level of nutritional knowledge and healthy eating practices among primary school pupils in Ikenne Local Government Area of Ogun State, Nigeria.

\section{Hypotheses}

1) There will be no significant differential effect of training programmes on student's level of nutritional knowledge and healthy eating practices.

2) There will be no significant interaction effect of training programmes and gender on student's level of nutritional knowledge and healthy eating practices.

\section{Methods}

\subsection{Participants and Design}

The study is a pre-post test quasi-experimental with $3 \times 2$ factorial design. The various factors are groups (experimental groups); and gender which was observed two levels (male and female). A total of 240 primary school pupils (Primary 5 and 6 ) randomly selected from three public primary schools and a purposive sample is drawn from the population based on willingness to undergo motivational programs. Pupils were randomly assigned to the three experimental groups based on their gender into each of the group.

\subsection{Instruments}

This study has three sections; first section obtained information about student demographic characteristics such as class, gender and age. The second section was the Healthy Eating Lifestyle Questionnaire (HELQ). HELQ is a 30 positively worded scale in which the participants were asked to indicate the frequency of adopting 30 positively stated healthy eating lifestyle or habits. The HELQ is measure using a 4-point likert scale ranging from 1 (not at all true of me) to 4 (exactly true of me) with Cronbach's alpha of .769. 


\subsection{Procedures}

This research has developed life modification and nutrition education intervention on healthy eating practices program and pupils freely volunteered themselves to participate for 5 days period. They were randomly assigned into three treatment groups. Each of the experimental groups were given 5 sessions intervention programme within the duration of 5 days (One week). There is no control group since the intentions of the researchers were not to revalidate the effectiveness of the packages but to find out which one is more effective in fostering healthy eating practices. Basically, procedure was carried out in three stages as follows:

(a) Pre-treatment stage involved a familiarization visit to the two selected schools, which focused on general introduction, establishment of rapport as well as administration of the instruments to all the primary 5 and 6 pupils. A simple random sampling procedure was used to select 240 participants. To ensure that every student have equal chance to being selected, the word 'YES' and 'NO' were written on separate slips and placed in a plastic bowl. After thorough reshuffling, students were asked to pick the slips of paper, those with 'YES' were used for the study. The selection of student based on self-efficacy was also put into consideration using the efficacy scale. After the selection process, participants were briefed on the objective of the study and the benefits therein. The instrument was administered to both the experimental and control groups.

(b) The treatment Session: The participants were subjected to five (5) days of treatment programme. In each of the treatment group the participants had five sessions of the therapy. Each session took 45 minutes.

(c) Post-treatment Session: This is the evaluation stage. At the end of the five (5) days training were not subjected to post-test using the same instrument until 6 weeks after to see result arising from training. The 6 weeks after post-test was to ensure that the pupils have really put into use what they were exposed to during the training section.

\subsection{Method of Analysis}

Analysis of covariance (ANCOVA) was adopted to analyze data generated and to test the hypothesis at 0.05 significant level. Analysis of covariance (ANCOVA) was utilized to investigate the joint effect of the independent variables on the dependent variable.

\section{Results}

Table 1. Analysis of covariance (ANCOVA) on the effectiveness of training programmes on participants' nutritional knowledge and healthy eating practices

\begin{tabular}{lllllll}
\hline Source & Variable & Type III Sum of Square & Df & Mean Square & F & P \\
\hline \multirow{3}{*}{ Group } & LM & 24.876 & 1 & 24.876 & 4.107 & .003 \\
& NE & 23.009 & 1 & 23.009 & 3.354 & .000 \\
& LM \& NE & 27.765 & 1 & 27.765 & 5.987 & .007 \\
\hline
\end{tabular}

$\mathrm{LM}=$ Lifestyle modification, $\mathrm{NE}=$ Nutrition education, $\mathrm{LM} \& \mathrm{NE}=$ Lifestyle modification and Nutrition education.

Table 1 revealed that the treatment programmes have statistical significant differential effect in enhancing participants' nutritional knowledge and healthy eating practices. Among the treatment programmes, the group exposed to life modification and nutrition education had more enhanced healthy eating practices $\left(\mathrm{F}_{1,236}\right)=5.987$; $\mathrm{P}$ $=.007)$ compared to their counterparts in life modification $\left.\left(\mathrm{F}_{1,236}\right)=4.107 ; \mathrm{P}=.003\right)$ and/or nutrition education $\left.\left(\mathrm{F}_{1,236}\right)=3.354 ; \mathrm{P}=.000\right)$. Therefore, the hypothesis that stated no significant differential effect of treatments on participants' nutritional knowledge and healthy eating practices scores cannot be sustained. It showed that all the three groups are effective to increase participants' nutritional knowledge and healthy eating practices. 
Table 2. Analysis of covariance of participants scores in nutritional knowledge and healthy eating practices

\begin{tabular}{lllllll}
\hline Sources & SS & Df & MS & F-value & F. critical & P \\
\hline Rows & 173.322 & 1 & 173.322 & 17.049 & 11.321 & .000 \\
Columns & 19.876 & 1 & 19.876 & 8.517 & & .011 \\
Interaction & 96.524 & 2 & 48.262 & 10.055 & & .007 \\
Within & 989.807 & 236 & 17.589 & & & \\
\hline
\end{tabular}

Table 3. Rows and columns of adjusted Y-means compared

\begin{tabular}{lll}
\hline & Males & Females \\
\hline Lifestyle modification (LM) & (a) 91.037 & (c) 97.543 \\
Nutrition education (NE) & (b) 88.958 & (d) 94.171 \\
Lifestyle modification and Nutrition education (LM \& NE) & (e) 103.256 & (f) 112.009 \\
\hline
\end{tabular}

The results presented in Table 2 and 3 indicated that lifestyle modification (LM), nutrition education (NE) and when combined as a treatment programmes were effective in fostering participants' nutritional knowledge and healthy eating practices. The results further reveal that there is a significant difference in the participants' nutritional knowledge and healthy eating practices managed with LM, NE and those treated with LM and NE $\left(\mathrm{F}_{2,236}=10.055, \mathrm{P}=.007\right)$. Enhancing participants' nutritional knowledge and healthy eating practices was more pronounced in the group exposed to lifestyle modification and nutrition education (LM \& NE) for both male and female compared to their counterparts exposed to LM or NE alone. Thus, the earlier stated hypothesis of no significant differential effect of treatments on participants' healthy eating practices based on gender was rejected. It is worth to note that in all the treatment groups Female participants benefit better when compared to their male counterparts.

\section{Discussion}

The outcome of this study has established the effectiveness of lifestyle modification (LM), nutrition education (NE) and when combined as a treatment in enhancing participants' nutritional knowledge and healthy eating practices. This was evident by the enhancement in participants' nutritional knowledge and healthy eating after 6 weeks exposure to the training. This indicates not only the effectiveness of the three treatment strategies but also the utilization of treatment gains by the participants as well. These results were in line with the findings of previous researchers on nutritional knowledge enhancement after training and healthy eating habits. For instance, the findings of Audu (2013), Onyeneke, Nwajiuba, Igberi, Amadi, Anosike, Oko-Isu., Munonye, Uwadoka, and Adewale (2019) corroborates the outcome of this study as they found out that nutrition education is an effective means of alerting of individuals of the need for nutrition improvement and step towards improving food habits. Also, Baker, Simpson, Lloyd, Bauman, and Singh (2011), Barte et al., (2011), and Wadden, Webb, Moran, and Bailer (2012) confirmed the effectiveness of lifestyle modifications in helping individuals to resolve the problem of obesity-related comorbidities, improved the effectiveness of diet and weight management.

Another significant finding of this study is the significant difference it the participants' nutritional knowledge and healthy eating practices. The effectiveness is in favour of the combined treatment of lifestyle modification (LM) and nutrition education (NE). This difference could be based on the premise that participants' participants' nutritional knowledge and healthy eating are influenced by so many factors that could be social, personal, and environmental. Therefore, the combined treatment of lifestyle modification (LM) and nutrition education (NE) helped out in the weight management and prudent diet. Besides, the addition of psychological component further improved the effectiveness of diet and weight management interventions (Stephens, Cobiac, \& Lennert, 2014).

One other significant finding of the study was the positive influence of the training programmes on females' nutritional knowledge and healthy eating behaviour compared to their male counterparts. The gender difference accounted for cannot be empirically explained in this study. The only deduction here could be as a result that many females today are trying to build their body as beauty model by being watchful of what they eat. Though, there is no substantial proof for this, one can still say that every female want to look good.

\section{Conclusion and Recommendation of Findings}

Based on the finding of the study, it is concluded that there was a significant differential effectiveness of lifestyle 
modification (LM), nutrition education (NE) and when combined as a treatment enhanced participants' nutritional knowledge and healthy eating practices. The differences observed on the nutritional knowledge and healthy eating behaviour of the pupils is not in fact due to chance but the effect of training programme. Gender had statistical significant influence on the nutritional knowledge and healthy eating behaviour after the treatment.

The findings have effectively demonstrated that the treatment packages could be used as veritable tools in equipping adolescents with necessary skills that can foster good relationship with selves and others, therefore, bringing about better future and peaceful co-existence among the people of the world.

This study has significantly shown the effectiveness of the treatment programmes in enhancing the participants' knowledge of their personal food intake and this knowledge has increased the individuals' potential and decisions to continue to utilize nutrition information in their daily food choices and monitoring salt and sugar intake to prevent diet-related illness. It is therefore concluded that these treatment programmes has helped the pupils assessed their degree of control over their daily dietary habits as well as psycho-sociological thoughts associated with daily dietary habits.

Based on the findings of the study, the following are recommended:

1) The information can be used by students, educators, and healthcare professionals to increase nutrition knowledge of every child right from their homes.

2) Guidance counsellors, social workers, and community health workers can use this information from this study to encourage and support discussion to develop nutrition based programs in all homes and schools.

3) Federal and state governments should organise community-based nutrition education programme for the people. This will in turn help the citizens develop positive nutritional life styles.

\section{Competing Interests Statement}

The authors declare that there are no competing or potential conflicts of interest.

\section{References}

Anabwani, G. (2015). Nutritional issues in adolescents. Nestle news article. Retrieved November 23, 2018, from www.nestlenutrition.institution.org

Audu, A. J. (2013). Effect of nutrition education programme on food-related-knowledge and attitudes of literate women in Pankshin Community, Nigeria. Mediterranean Journal of Social Sciences, 4(15), 35-41

Ayodele, K. O., \& Oke, K. (2017). Knowledge, attitude, and practice of food vendors on food hygiene in higher institutions in Ogun State, Nigeria. Nigeria Journal of Social Work Education, 16, 73-82.

Baker, M. K., Simpson, K., Lloyd, B., Bauman, A. E., \& Singh, M. A. (2011). Behavioral strategies in diabetes prevention programs: A systematic review of randomized controlled trials. Diabetes Res. Clin. Pract., 91, 1-12. https://doi.org/10.1016/j.diabres.2010.06.030

Barte, J. C., Ter Bogt, N. C., Bogers, R. P., Teixeira, P. J. Blissmer, B., Mori, T. A., \& Bemelmans, W. J. (2010). Maintenance of weight loss after lifestyle interventions for overweight and obesity, a systematic review. Obes. Rev., 11, 899-906. https://doi.org/10.1111/j.1467-789X.2010.00740.x

Bargiota, A., Delizona, M., Tsitouras, A., \& Koukoulis, G. (2013): Eating habits and factors affecting food choices of adolescents living in rural areas. PubMed journal, 12(2), 246-253. https://doi.org/10.14310/horm.2002.1408

Buxton, C. (2013). Ghanaian junior high school adolescent's dietary practices and food preferences: Implication for public health concern. Journal of nutrition and food Sciences, 4, 297-303.

Chadwick, P. M., Crawford, C. C., \& Ly, L. L. (2013). Human food choice and nutritional interventions. Nutrition Bulletin, 38(1), 36-42. https://doi.org/10.1111/nbu.12005

Chu, Y. L., Farmer, A., Fung, C., Kuhle, S., Storey, K. E., \& Veugelers, P. J. (2013). Involvement in home meal preparation is associated with food preference and self-efficacy among Canadian children. Public health nutrition, 16(01), 108-112. https://doi.org/10.1017/S1368980012001218

Colley, R. C., Garriguet, D., Janssen, I., Craig, C. L., Clarke, J., \& Tremblay, M. S. (2011). Physical activity of Canadian children and youth: accelerometer results from the 2007 to 2009 Canadian Health Measures Survey.

Cunningham-Sabo, L., \& Lohse, B. (2014). Impact of a school-based cooking curriculum for fourth grade students 
on attitudes and behaviors is influenced by gender and prior cooking experience. Journal of nutrition education and behavior, 46(2), 110-120. https://doi.org/10.1016/j.jneb.2013.09.007

Demory-Luce, D., \& Motil, K. (2016). Adolescent eating habits. Retrieved January 11, 2017, from www.Uptodate.com

Fitzgerald, A., Heary, C., Nixon, E., \& Kelly, C. (2010). Factors influencing the food choices of children and adolescents: A qualitative investigation. Oxford journal Health Promotion International, 25(3), 289-298. https://doi.org/10.1093/heapro/daq021

Franchi, M. (2012). Food choice: beyond the chemical content. International Journal of Food Sciences And Nutrition, 63(Suppl 11), 72-8. https://doi.org/10.3109/09637486.2011.632403

Isa, K., \& Masuri, M. (2011): The association of breakfast consumption habits: snacking behavior and body mass index among university students. Journal of Food and Nutrition, 1(2), 55-60. https://doi.org/10.5251/ajfn.2011.1.2.55.60

Leverton, R. (1974). What is nutrition education? Journal of American Dietetics Association, 64, 17-21.

Lewis, K. J. (1976). Nutrition education in changing world. In S. S. Laura (ed.), Overview: Nutrition education research in the policy arena. Proceeding of the penn state conferencs. Directions for Nutrition Education Research. Pennsylvania state university, Pennsylvania, USA, July-Oct. 1980.

Li, C., Goran, M. I., Kaur, H., Nollen, N., \& Ahluwalia, J. S. (2007). Developmental trajectories of overweight during childhood: role of early life factors. Obesity, 15(3), 760-771. https://doi.org/10.1038/oby.2007.585

Lokadhia, M. (2013): University Students Dietary Patterns: A case of a University in Zimbabue. Journal of Emerging Trends in Educational Research and Policy Studies, 4(1), 191-197.

McFerran, B., Dahl, D. W., Fitzsimons, G. J., \& Morales, A. C. (2013). I'll Have What She's Having: Effects of Social Influence and Body Type on the Food Choices of Others. Journal of Consumer Research, 6(36), 915-929. https://doi.org/10.1086/644611

Nonnemaker, J. M., Morgan-Lopez, A. A., Pais, J. M., \& Finkelstein, E. A. (2009). Youth BMI trajectories: evidence from the NLSY97. Obesity, 17(6), 1274-1280. https://doi.org/10.1038/oby.2009.5

Onyeneke, R., Nwajiuba, C., Igberi, C., Amadi, M., Anosike, F., Oko-Isu A., Munonye, J., Uwadoka, C. \& Adewale, A. (2019). Impacts of caregivers' nutrition knowledge and food market accessibility on preschool children's dietary diversity in remote communities in South-east, Nigeria. Sustainability, 11, 1688. https://doi.org/10.3390/su11061688

Onyiriuka, A., Umuru, D., \& Ibeawuchi, A. (2013). Eating habits and obesity in Adolescents. South African journal, 7(3), 108-112. https://doi.org/10.7196/sajch.529

Onyiriuka, A., Egbagbe, E., \& Onyiriuka, E. (2013). Snack consumption pattern among Adolescent girls in Nigerian Urban Secondary Schools. International journal of child and Adolescent Health, 6(3), 311-317.

Pai, H.-L., \& Contento, I. (2014). Parental perceptions, feeding practices, feeding styles, and level of acculturation of Chinese Americans in relation to their school-age child's weight status. Appetite, 80, 174-182. https://doi.org/10.1016/j.appet.2014.04.029

Skardal, M., Western, M., Ask, A., \& Overby, N. (2014): Socioeconomic differences in selected dietary habits among 13-14 years old: A Cross-Sectional Study. Food and Nutrition Journal, 58, 1-3. https://doi.org/10.3402/fnr.v58.23590

Stephens, S. K., Cobiac, J. K., \& Lennert, V. J. (2014). Improving diet and physical activity to reduce population prevalence of overweight and obesity: An overview of current evidence. Prev. Med, 62, 167-178. https://doi.org/10.1016/j.ypmed.2014.02.008

Stevenson, C., Doherty, G., Barnett, J., Muldoon, O. T., \& Trew, K. (2007). Adolescents' views of food and eating: Identifying barriers to healthy eating. Journal of adolescence, 30(3), 417-434. https://doi.org/10.1016/j.adolescence.2006.04.005

Wadden, T. A., Webb, V. L., Moran, C. H., \& Bailer, B. A. (2012). Lifestyle modification for obesity: New developments in diet, physical activity, and behavior therapy. Circulation, 125, 1157-1170. https://doi.org/10.1161/CIRCULATIONAHA.111.039453

Wang, Y., \& Lim, H. (2012). The global childhood obesity epidemic and the association between socio-economic status and childhood obesity. International Review of Psychiatry, 24(3), 176-188. 
https://doi.org/10.3109/09540261.2012.688195

Winson, A. (2008). School food environments and the obesity issue: content, structural determinants, and agency in Canadian high schools. Agriculture and Human Values, 25(4), 499-511. https://doi.org/10.1007/s10460-008-9139-8

Winson, A. (2010). The demand for healthy eating: Supporting a transformative food "movement". Rural Sociology, 75(4), 584-600. https://doi.org/10.1111/j.1549-0831.2010.00033.x

\section{Copyrights}

Copyright for this article is retained by the author(s), with first publication rights granted to the journal.

This is an open-access article distributed under the terms and conditions of the Creative Commons Attribution license (http://creativecommons.org/licenses/by/4.0/). 